\title{
Corrigendum
}

\section{Allosteric Modulation of $\mathrm{GAB}_{\mathrm{AA}}$ Receptor Subtypes: Effects on Visual Recognition and Visuospatial Working Memory in Rhesus Monkeys}

Paul L Soto, Nancy A Ator, Sundari K Rallapalli, Poonam Biawat, Terry Clayton, James M Cook and Michael R Weed

Neuropsychopharmacology (2013) 38, 2553; doi:10.1038/npp.2013.162

Correction to: Neuropsychopharmacology advance online publication, 26 June 2013; doi:10.1038/npp.2013.137
In this article, there is an error in the title. The correct title is 'Allosteric Modulation of $\mathrm{GABA}_{\mathrm{A}}$ Receptor Subtypes: Effects on Visual Recognition and Visuospatial Working Memory in Rhesus Monkeys.' 